\title{
Comparison of Analytical Method and Different Finite Element Models for the Calculation of Leakage Inductance in Zigzag Transformers
}

\author{
Kamran Dawood ${ }^{1, *}$, Fatih Isik ${ }^{2}$, Guven Komurgoz ${ }^{1}$ \\ ${ }^{1}$ Department of Electrical Engineering, Istanbul Technical University, \\ Maslak, 34467 Sariyer, Istanbul, Turkey \\ ${ }^{2}$ Research \& Development Director, Astor Transformers, \\ 34906, Ankara, Turkey \\ kamransdaud@yahoo.com
}

\begin{abstract}
A zigzag transformer is a key segment of the electric power system. The optimal design of the zigzag transformer is important for transformer designers to provide a required return path for earth faults and to ensure proper operation of a power system. The two most important parameters of the zigzag transformers are no-load losses and leakage impedance. The accurate calculation of both factors helps to minimize the overall cost of the transformer. Therefore, the prediction of leakage reactance in the zigzag transformer using analytical or numerical methods is an essential part of the early designing stages of the transformer. This paper provides several two- and three-dimensional finite element models. The main purpose of these models is to evaluate the accuracy of the different models for the calculation of the leakage reactance. An analytical formula and a complete procedure for the calculation of the leakage reactance in the zigzag transformer are also provided, which will help the researchers and transformer designer to optimize this type of transformer. The prototype is also manufactured and tested to verify the accuracy of the analytical method and finite element models for the calculation of the leakage reactance. The simulation and experimental results show that the finite element calculation cannot only obtain accurate leakage reactance values (magnetostatic analysis), but also provides better accuracy in the no-load losses (transient analysis).
\end{abstract}

Index Terms-Finite element method; Grounding transformer; Leakage reactance; Magnetostatics analysis; Transient analysis; Zigzag transformer.

\section{INTRODUCTION}

Transient overvoltages, short-circuit withstands capability, basic insulation level, and other important factors of the power system depend on the neutral grounding. The impedance to ground faults can be decreased by using grounding transformers. The level of ground fault current can also be decreased by using the grounding transformers. Two main configurations of three-phase grounding transformers are:

Manuscript received 3 June, 2021; accepted 1 February, 2022.

This research was supported by the TUBİTAK under Grant No. 118C109; Istanbul Technical University Bilimsel Araştırma Projeleri under Grant No. MGA-2020-42527.
- Interconnected star or zigzag connections;

- Wye-delta grounding transformer.

Zigzag transformers are preferred due to their lower cost and smaller size for the same value of the zero-sequence impedance in wye-delta grounding transformers. Zigzag transformers are found everywhere in the contemporary world. As their number increases, accurate calculation of leakage reactance becomes an important issue in maintaining the comfortable working of the zigzag transformer.

The zigzag transformer is built with copper windings, a soft magnetic material (silicon steel), and high-end insulation materials. Leakage reactance is one of the most important parameters of the zigzag transformer because the main purpose of the zigzag transformer is to provide a low leakage reactance to give a path for zero sequence components during the fault conditions. Using finite element models and analytical equations, a variety of changes can be made to the geometry and ampere-turns of the zigzag transformer to optimize the impact of leakage reactance and fulfilling the customer requirements. The voltage increase in the unfaulted phases is also prevented by the zigzag transformer.

Zigzag transformers are also known as interconnected star windings, and the zigzag transformer has some characteristics of the delta and the star connection, and the advantages of both delta and star connections.

Zigzag transformers are used as a grounding transformer; the main advantages of the zigzag transformer for the power systems are [1]-[5]:

- The zigzag transformer performs harmonic mitigation and terminates harmonics. The zigzag transformer can be used in a power system to trap triplet harmonic currents, i.e., $3^{\text {rd }}, 9^{\text {th }}, 15^{\text {th }}$, and $21^{\text {st }}$ harmonics. Zigzag transformers are installed near the loads that produce higher triplet harmonic currents and minimize the undesirable effects of the triplet harmonic.

- Zigzag transformers provide cheaper grounding on the transformers. It helps components of the power system and decreases the stress of the voltage under the fault currents. The zigzag transformer also provides insulation 
between the power system components and the ground, so that the power system components may not be affected by the fault current.

- Due to the low internal winding impedance, zigzag transformers are more effective for grounding purposes and provide a better solution for grounding the power system. Zigzag transformers have a low leakage impedance value, which allows the triple-harmonics of the excitation current and the zero-sequence currents to flow through it because there is no opposition to their flow except the small value of the leakage reactance of the zigzag transformers.

The leakage reactance in the transformer can be calculated with analytical techniques, numerical methods, and experimental tests. The leakage reactance of the transformer can also be calculated by using the reluctance network modeling [6].

Numerical techniques are accurate, but this method is time-consuming. Reluctance network modeling is faster but less accurate as compared to the numerical method. Due to the higher accuracy, compared to the other analytical method, the Rogowski method is one of the efficient analytical techniques that can be used effectively to evaluate leakage reactance [7].

The change in the dimension of the transformer winding can significantly affect the leakage reactance, resulting in the change in the short-circuit current and the short-circuit impedance of the transformer [8]. The size of the internal winding can also be determined by leakage reactance [9]. Magnetic traps to harmonics are also affected by the leakage reactance [10]. In [11]-[18], different analytical methods and finite element models are presented to evaluate leakage reactance in the different types of winding connections. However, a comparison of the different methods for evaluating leakage reactance applied to zigzag configuration transformers for determining the accuracy of these methods is still missing. Hence, this work explains the determination of the leakage reactance in the zigzag transformer in detail, i.e., the calculation of the leakage reactance by analytical methods and the finite element method. Furthermore, several finite element models are compared for the accurate calculation of the leakage reactance.

Different magnetostatic analysis and transient analysis are performed to evaluate the accuracy of the finite element analysis for values of the leakage reactance and no-load losses in the zigzag transformers. For the estimation of the leakage reactance four different models are used, namely, three-phase three-dimensional, single-phase threedimensional, three-phase two-dimensional, and single-phase two-dimensional. The analytical method is derived from the available analytical equations and the results of the analytical method are also compared and investigated by finite element simulations and experimental tests.

\section{REACTANCE IN ZIGZAG TRANSFORMERS}

As a consequence of international standards and manufacturing tolerances, leakage reactance calculation is one of the important subjects for transformer designers. One important question for transformer designers is how different parameters affect the overall leakage reactance of the zigzag transformer. In this paper, a comparative study of a leakage reactance calculation for the zigzag transformer is presented.

The short-circuit performance of the transformer is also related to the leakage reactance. The leakage reactance depends on the ampere-turns and geometry of the transformer, all of which can be analysed by using an analytical method or numerical method. Evaluating leakage reactance in the zigzag transformer using analytical and numerical techniques saves time, reduces the number of experiments, and prototypes. These methods can accurately predict the leakage reactance within the zigzag transformer, which contributes to optimization of the overall zigzag transformer design.

For the flow of the positive and negative sequence currents, zigzag connections pose a high magnetization impedance. However, to improve the flow of tripleharmonics and zero-sequence currents, zigzag transformers have a lower leakage reactance because they provide a path for zero-sequence currents coming from ground faults. Zero-sequence currents in the power system come mainly from unbalanced loads and faults involving grounding. That is why it is in the greater interest of the zigzag transformer designers to give an accurate value of the leakage reactance and guarantee leakage inductance levels in the range of the international standards. The IEC 60076-1 standard mandates tolerance of $\pm 10 \%$ for zigzag transformers. Equation (1) shows the Rogowski method for the evaluation of leakage reactance [13]:

$$
\begin{gathered}
\mathrm{X}=2 \pi \times \mathrm{f} \frac{\pi \mathrm{N}^{2} \mu_{\mathrm{O}}}{\mathrm{H}_{\mathrm{eq}}} \times \sum \mathrm{ATD}, \\
\sum \mathrm{ATD}=\frac{1}{3}\left(\mathrm{~B}_{\mathrm{HV}} \times \mathrm{D}_{\mathrm{HV}}\right)+\left(\mathrm{B}_{\mathrm{HL}}+\mathrm{D}_{\mathrm{HL}}\right)+\frac{1}{3}\left(\mathrm{~B}_{\mathrm{LV}} \times \mathrm{D}_{\mathrm{LV}}\right),
\end{gathered}
$$

where $\mathrm{N}, \mathrm{f}, \mathrm{ATD}, \mu_{\mathrm{o}}, \mathrm{B}_{\mathrm{HV}}, \mathrm{B}_{\mathrm{HL}}$, and $\mathrm{B}_{\mathrm{LV}}$ are the number of turns in the high voltage winding, frequency, ampere-turn density, free space permeability, radial depth of the high voltage winding, the gap between low voltage (LV) and high voltage $(\mathrm{HV})$ windings, and $\mathrm{LV}$ winding. $\mathrm{D}_{\mathrm{HV}}, \mathrm{D}_{\mathrm{HL}}$, and $D_{L V}$ are the mean diameter of the $H V$ winding, the gap between the LV and HV windings, and the LV winding. The equivalent height of the winding can be represented as $\mathrm{H}_{\mathrm{eq}}$

$$
\mathrm{H}_{\mathrm{eq}}=\frac{\mathrm{H}_{\mathrm{w}}}{\mathrm{K}_{\mathrm{R}}} .
$$

$H_{w}$ is the average height of the windings, and $K_{R}$ is the Rogowski factor

$$
\mathrm{K}_{\mathrm{R}}=1-\frac{1-\mathrm{e}\left(\frac{-\pi \times \mathrm{H}_{\mathrm{w}}}{\mathrm{B}_{\mathrm{LV}}+\mathrm{B}_{\text {HL }}+\mathrm{B}_{\text {HV }}}\right)}{\frac{\pi \times \mathrm{H}_{\mathrm{w}}}{\mathrm{B}_{\mathrm{LV}}+\mathrm{B}_{\text {HL }}+\mathrm{B}_{\mathrm{HV}}}} .
$$

The leakage reactance in the zigzag and delta (or star) 
transformers can be calculated by using (5) [18]. As shown in (5), the leakage reactance in the zigzag transformer can be calculated in three pairs of winding (three steps), i.e., between the high voltage and zig winding, the high voltage and zag winding, and the zig and zag winding

$$
\mathrm{X}_{\text {star-zigag }}=\frac{1}{2}\left[\mathrm{X}_{\mathrm{HV}-\mathrm{zig}}+\mathrm{X}_{\mathrm{HV}-\text { zag }}\right]+\frac{1}{6}\left[\mathrm{X}_{\text {zig-zag }}\right] .
$$



Fig. 1. Geometric dimensions.

When the zig-zag is on the high voltage side, (5) can be rewritten as

$$
\mathrm{X}_{\text {zigaag-sar }}=\frac{1}{2}\left[\mathrm{X}_{\mathrm{LV}-\mathrm{zig}}+\mathrm{X}_{\mathrm{LV}-\mathrm{zag}}\right]+\frac{1}{6}\left[\mathrm{X}_{\text {zig-zag }}\right] \text {. }
$$

The leakage reactance between the pair of low voltage and zig winding can be calculated by using (7)

$$
\mathrm{X}_{\mathrm{LV}-\mathrm{ig}}=2 \pi \mathrm{f} \times \frac{\pi \mathrm{N}^{2} \mu_{\mathrm{o}}}{\mathrm{H}_{\mathrm{LV}-\mathrm{iig}}} \times \sum_{\mathrm{ATD}_{\mathrm{LV}-\mathrm{Zig}}}
$$

where $\sum \mathrm{ATD}_{\mathrm{LV} \text {-zig }}$ and $\mathrm{H}_{\mathrm{LV} \text {-zig }}$ are the ampere-turn density and the equivalent height of the LV and zig winding. Equations (8) and (9) can be used to calculate $\sum \mathrm{ATD}_{\mathrm{LV} \text {-zig }}$ and $\mathrm{H}_{\mathrm{LV}-\mathrm{zig}}$ :

$$
\begin{gathered}
\sum \mathrm{ATD}_{\mathrm{LV}-\text { zig }}=\frac{1}{3}\left(\mathrm{~B}_{\text {zig }} \times \mathrm{D}_{\text {zig }}\right)+ \\
+\left(\mathrm{B}_{1}+\mathrm{D}_{1}\right)+\frac{1}{3}\left(\mathrm{~B}_{\mathrm{LV}} \times \mathrm{D}_{\mathrm{LV}}\right), \\
\mathrm{H}_{\mathrm{LV}-\text { zig }}=\frac{\mathrm{H}_{\mathrm{w} 1}}{\mathrm{~K}_{\mathrm{R} 1}} .
\end{gathered}
$$

$\mathrm{H}_{\mathrm{w} 1}$ is the average height of the low voltage and zig winding. $\mathrm{B}_{\mathrm{zig}}, \mathrm{D}_{\mathrm{zig}}$, and $\mathrm{B}_{1}, \mathrm{D}_{1}$ are the radial depth and mean diameter of the zig winding and the radial depth and mean diameter of the gap between LV and zig winding. Figure 1 shows the geometrical dimension of the equations from (8) to $(18)$.

The Rogowski factor of the LV and the zig winding can be calculated by using (10)

$$
\mathrm{K}_{\mathrm{R} 1}=1-\frac{1-\mathrm{e}\left(\frac{-\pi \times \mathrm{H}_{\mathrm{w}}}{\mathrm{B}_{\text {zig }}+\mathrm{B}_{1}+\mathrm{B}_{\mathrm{LV}}}\right)}{\frac{\pi \times \mathrm{H}_{\mathrm{w}}}{\mathrm{B}_{\text {iig }}+\mathrm{B}_{1}+\mathrm{B}_{\mathrm{LV}}}} .
$$

The leakage reactance between the pair of the low voltage and the zag winding can be calculated using (11)

$$
\mathrm{X}_{\mathrm{LV}-\mathrm{zag}}=2 \pi \mathrm{f} \times \frac{\pi_{\mathrm{N}}^{2} \mu_{\mathrm{o}}}{\mathrm{H}_{\mathrm{LV}-\mathrm{zag}}} \times \sum_{\mathrm{ATD}_{\mathrm{LV}-\mathrm{Zag}}},
$$

where $\sum \mathrm{ATD}_{\mathrm{LV} \text {-zag }}$ and $\mathrm{H}_{\mathrm{LV} \text {-zag }}$ are ampere-turn density and equivalent height of the $\mathrm{LV}$ and zag winding. Equations (12) and (13) can be used to calculate $\sum \mathrm{ATD}_{\mathrm{LV}-\mathrm{zag}}$ and $\mathrm{H}_{\mathrm{LV} \text { - }}$ zag:

$$
\begin{gathered}
\sum \mathrm{ATD}_{\mathrm{LV}-\mathrm{zag}}=\frac{1}{3}\left(\mathrm{~B}_{\text {zag }} \times \mathrm{D}_{\text {zag }}\right)+ \\
+\left(\mathrm{B}_{3}+\mathrm{D}_{3}\right)+\frac{1}{3}\left(\mathrm{~B}_{\mathrm{LV}} \times \mathrm{D}_{\mathrm{LV}}\right), \\
\mathrm{H}_{\mathrm{LV}-\text { Zag }}=\frac{\mathrm{H}_{\mathrm{w} 2}}{\mathrm{~K}_{\mathrm{R} 2}} .
\end{gathered}
$$

$\mathrm{H}_{\mathrm{w} 2}$ is the average height of the low voltage and zag winding. $\mathrm{B}_{\mathrm{zag}}, \mathrm{D}_{\mathrm{zag}}$, and $\mathrm{B}_{3}, \mathrm{D}_{3}$ are the radial depth and mean diameter of the zag winding, and the radial depth and mean diameter of the gap between the LV and zag winding.

The Rogowski factor of the LV and zag winding can be calculated using (14)

$$
\mathrm{K}_{\mathrm{R} 2}=1-\frac{1-\mathrm{e}\left(\frac{-\pi \times \mathrm{H}_{\mathrm{w}}}{\mathrm{B}_{\mathrm{zag}}+\mathrm{B}_{3}+\mathrm{B}_{\mathrm{LV}}}\right)}{\frac{\pi \times \mathrm{H}_{\mathrm{w}}}{\mathrm{B}_{\text {aag }}+\mathrm{B}_{3}+\mathrm{B}_{\mathrm{LV}}}} .
$$

The leakage reactance between the pair of zig and zag windings can be calculated by using (15)

$$
\mathrm{X}_{\text {zig-zag }}=2 \pi \mathrm{f} \times \frac{\pi \mathrm{N}^{2} \mu_{\mathrm{o}}}{\mathrm{H}_{\text {zig-zag }}} \times \sum_{\mathrm{ATD}_{\text {zig-zag }}},
$$

where $\sum \mathrm{ATD}_{\text {zig-zag }}$ and $\mathrm{H}_{\text {zig-zag }}$ are the ampere-turn density and the equivalent height of the zig and zag windings. Equations (16) and (17) can be used to calculate the $\sum \mathrm{ATD}_{\text {zig-zag }}$ and $\mathrm{H}_{\text {zig-zag: }}$ :

$$
\begin{gathered}
\sum \mathrm{ATD}_{\text {zig - zag }}=\frac{1}{3}\left(\mathrm{~B}_{\text {zig }} \times \mathrm{D}_{\text {zig }}\right)+ \\
+\left(\mathrm{B}_{2}+\mathrm{D}_{2}\right)+\frac{1}{3}\left(\mathrm{~B}_{\text {zag }} \times \mathrm{D}_{\text {zag }}\right) \\
\mathrm{H}_{\text {zig - zag }}=\frac{\mathrm{H}_{\mathrm{w} 3}}{\mathrm{~K}_{\mathrm{R} 3}} .
\end{gathered}
$$

$\mathrm{H}_{\mathrm{w} 3}$ is the average height of the zig and zag windings. $\mathrm{B}_{2}$, $\mathrm{D}_{2}$ are the radial depth and mean diameter of the gap between the zig and zag windings. The Rogowski factor of the zig and zag windings can be calculated using (18)

$$
\mathrm{K}_{\mathrm{R} 3}=1-\frac{1-\mathrm{e}\left(\frac{-\pi \times \mathrm{H}_{\mathrm{w}}}{\mathrm{B}_{\text {zig }}+\mathrm{B}_{2}+\mathrm{B}_{\text {zag }}}\right)}{\frac{\pi \times \mathrm{H}_{\mathrm{w}}}{\mathrm{B}_{\text {zig }}+\mathrm{B}_{2}+\mathrm{B}_{\text {zag }}}} .
$$




\section{NUMERICAL TECHNIQUES}

Due to the limitations of analytical methods, the use of numerical techniques for the solution of electromagnetic, magnetic, and electrostatic field problems is increasing day by day [19]-[21]. Numerical analysis can solve the irregular and complex geometrie and non-linear electric machine materials more appropriately as compared to the analytical method.

Finite element analysis is one of the most commonly used numerical techniques for solving magnetostatic problems. The finite element method can be used for the solution of differential equations in engineering fields such as magnetostatic analysis, thermal analysis, electromagnetic analysis, acoustics and vibration analysis, mechanics and structural analysis, fluid mechanic analysis, and transient analysis. In the finite element method, the solution mainly depends on the type of problem (mechanical, electromagnetic, linear, nonlinear, and thermal) and the type of software used for the computation. Nevertheless, the general structure is common to all finite element methods and can be divided into the three steps:

- Pre-processing;

- Processing;

- Post-processing.

In the pre-processing, the problem is defined. The first process of the pre-processing is to draw the geometry of the structure or problem which is needed to be solved and assign the suitable material properties for each of the objects. The finite element methods subdivide a geometry into simpler and smaller parts that are called "finite elements" and the main objective of the pre-processing in the finite element method is to discretize the structure into smaller elements and develop an appropriate finite element mesh. After mesh operation, the implementation of the boundary conditions and required contacts between the different objects and model components is needed. For the two-dimensional problems, triangle- or rectangle-based meshes can be used, and for the three-dimensional problem, tetrahedron meshes are preferred.

Figure 2 shows the steps of the pre-processing.

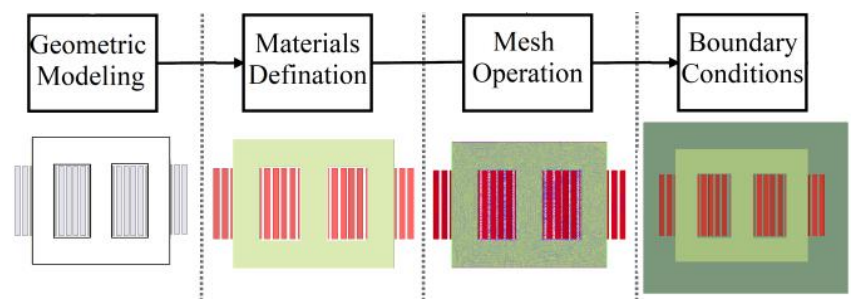

Fig. 2. Pre-processing.

In the processing step, the problem is assembled into the system equations using computational resources and an appropriate solution to the physical problem can be obtained.

The required solutions to the problem can be obtained in the post-processing step. The required solution and desired quantities (e.g., electromagnetic field, transient analysis, electrostatic field, stress, forces, temperature) can be represented by using plots, graphs, and tables. One of the most benefits of using the finite element method is to include the visual representation by using graphs, plots, and tables. Figure 3 shows the different types of representation during post-processing.
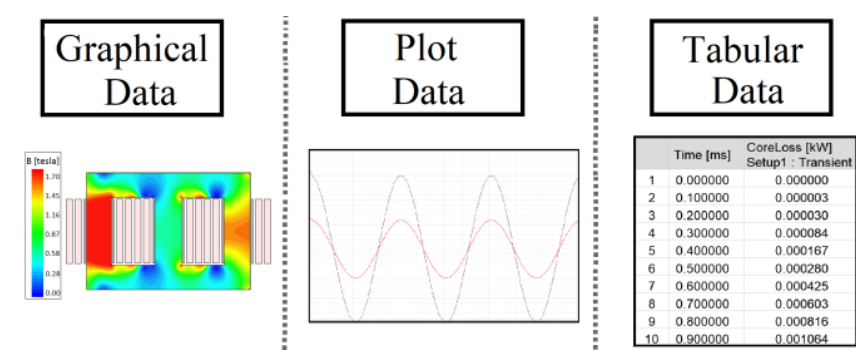

Fig. 3. Post-processing.

The use of finite element analysis is increasing rapidly due to its ability to solve real-world problems in a simple way. In transformer design, finite element analysis can be used to evaluate iron losses, copper losses, inrush current, vibration, stress, temperature, and electromagnetic forces.

The main aim of transformer designers is to construct a high-quality transformer at the lowest possible cost. In the zigzag transformer, the working of the transformer is mainly based on the leakage reactance. Designers of zigzag transformer can find the ideal value of the leakage reactance by changing the dimensions of the windings, the space between the windings, and the height of the windings.

Magnetostatic Problems. In transformers, leakage reactance, electromagnetic forces, inductance, capacitance, and other important factors involve magnetostatic problems. The analysis of the magnetostatics problem for the evaluation of the leakage reactance can be divided into four main parts:

- Modelling and materials definition;

- Generating and refining mesh;

- Current excitation and boundary conditions;

- Analysing the results.

Optimization of the transformer design for performance and efficiency can be achieved by performing all the steps of the analysis properly.

The two Maxwell equations given below in differential form can be applied to magnetostatic problems:

$$
\begin{gathered}
\nabla . \mathrm{B}=0, \\
\nabla \times H=\mathrm{J},
\end{gathered}
$$

where $\mathrm{J}, \mathrm{H}$, and $\mathrm{B}$ are the electric current density, magnetic field intensity, and magnetic flux density. The relationship between $\mathrm{H}$ and $\mathrm{B}$ in magnetic materials is given below

$$
\mathrm{B}=\mu . \mathrm{H} .
$$

In the equation above, $\mu$ is the permeability. The ferromagnetic materials, which are used in the manufacturing of the transformer and reactor magnetic circuits, possess a nonlinear B-H characteristic curve, and magnetic flux density is a function of the permeability and magnetic field intensity of the magnetic material. For the calculation of the leakage reactance, the permeability of the magnetic material must be kept high, and during the simulation, adding non-linear characteristics properties to the core is not compulsory. However, during the evaluation 
of the no-load and load losses, one must assign non-linear properties to the core of the transformer.

Using finite element methods, the leakage reactance of the zigzag transformer can be evaluated using the energy method. Equation (22) shows the formula for the calculation of the magnetic energy in the different parts of the transformer

$$
W_{\mathrm{mag}}=\int_{\text {vol }} \frac{1}{2} B \cdot H d V
$$

The calculated stored energy from the finite element method software can easily be converted to the inductance using (23)

$$
L=\frac{2 W_{m}}{I^{2}} .
$$

\section{ACCURACY of ANALytical Method AND Finite ELEMENT MODELS FOR THE LEAKAGE REACTANCE}

This section will compare the experimental results of the prototype transformer with the finite element method and analytical approach. The finite element results presented in this paper were obtained using the program ANSYS Maxwell. For the evaluation of the leakage reactance by the finite element method, four different models are used, namely three-phase three-dimensional, one-phase threedimensional, three-phase two-dimensional, and single-phase two-dimensional. Figures 4 and 5 show the mesh operation of the three-phase and single-phase two-dimensional models. The total number of mesh elements of three-phase two-dimensional and single-phase two-dimensional models are 40396 and 5950, respectively.

To validate the analytical method and numerical models, experiments were performed on the prototype transformer. Experimental measurements of the analysed transformer were performed in the test laboratory of the Astor Transformer Turkey, which is equipped with state-of-the-art testing devices.

For measuring voltage, current, power, and short-circuit impedance, the Yokogawa Electric WT500 power analyzer was used. All the tests are carried out on the transformer following the IEC-60076-1 standards. For the calculation of the no-load losses, the rated voltage was applied to the primary winding and other windings were open-circuited. A short-circuit test on the transformer was performed to determine the leakage reactance of the transformer.

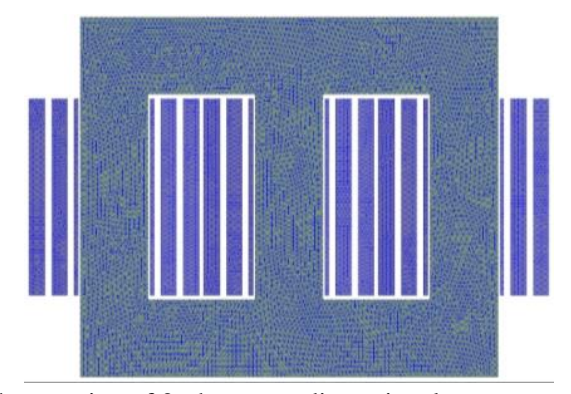

Fig. 4. Mesh operation of 3-phase two-dimensional.

In this study, leakage inductance and core losses were evaluated with the help of the numerical technique for the zigzag transformer with a power of $250 \mathrm{kVA}$ and a voltage level of $33 / 0.4 \mathrm{kV}$ with Znyn1 connections. After finding the leakage reactance results satisfactory, the zigzag transformer was manufactured with the same geometric dimensions. Figure 6 shows the image of the transformer during routine tests.

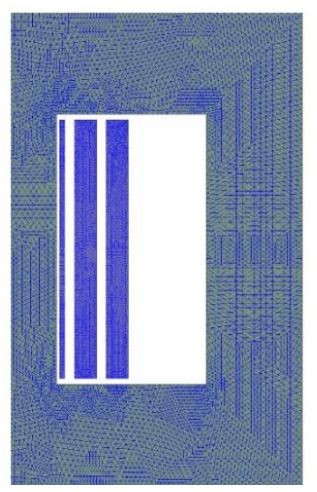

Fig. 5. Mesh operation of 1-phase two-dimensional.

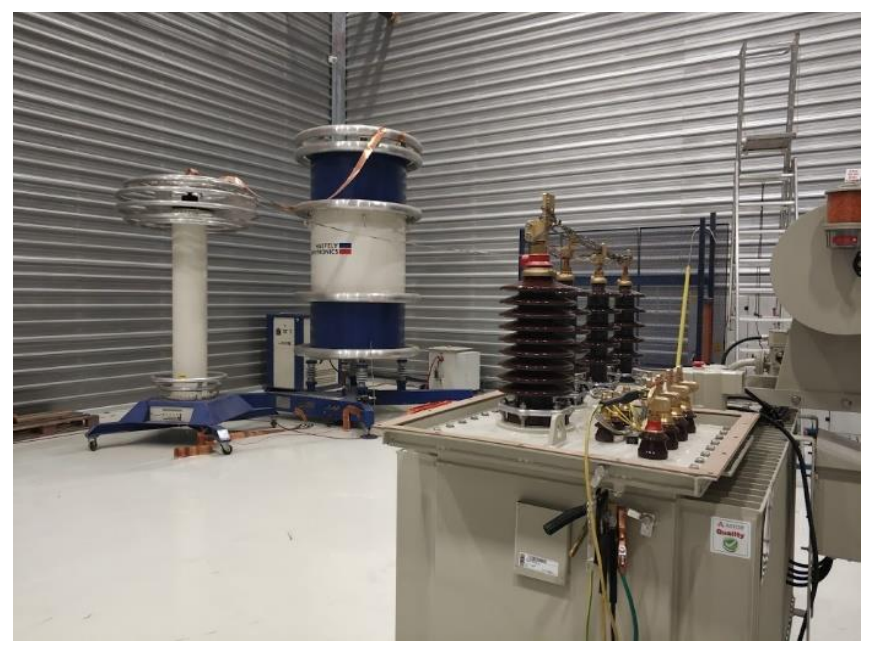

Fig. 6. Transformer during routine tests.

The basic design data of the prototype zigzag transformer are shown in Table I.

TABLE I. DESIGN DATA OF THE ZIGZAG TRANSFORMER.

\begin{tabular}{|c|c|}
\hline Connection & ZNyn 1 \\
\hline Power & $250 \mathrm{kVA}$ \\
\hline HV Voltage & $33 \mathrm{kV}$ \\
\hline LV Voltage & $0.4 \mathrm{kV}$ \\
\hline Zig + Zag turns & $1048+1048$ turns \\
\hline HV Current & $4.38 \mathrm{~A}$ \\
\hline Core Material & M5 cold rolled grain-oriented \\
& Steel \\
\hline Magnetic flux density & $1.651 \mathrm{~T}$ \\
\hline
\end{tabular}

Table II compares the calculation of the leakage reactance of the analytical method and finite element models with the experimental test.

TABLE II. CALCULATION OF LEAKAGE REACTANCE.

\begin{tabular}{|c|c|c|}
\hline Method & Leakage reactance \% & Difference \% \\
\hline 3-phase 3-D & 4.25 & 1.19 \\
\hline 1-phase 3-D & 4.39 & 4.52 \\
\hline 3-phase 2-D & 4.26 & 1.42 \\
\hline 1-phase 2-D & 4.40 & 4.76 \\
\hline Analytical & 3.92 & 6.67 \\
\hline Experimental & 4.2 & - \\
\hline
\end{tabular}


Figures 7 and 8 show the B-H and power loss curve of the core material of the zigzag transformer [11].

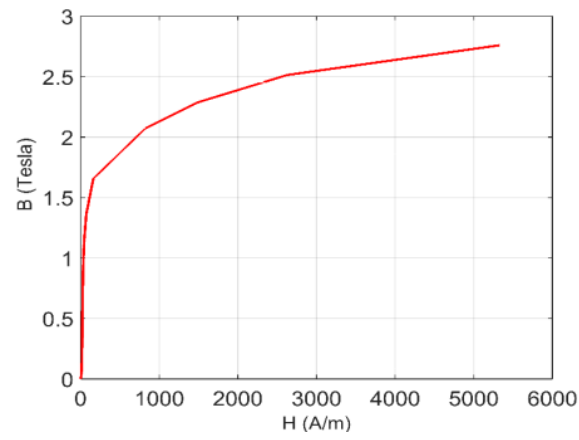

Fig. 7. B-H curve.

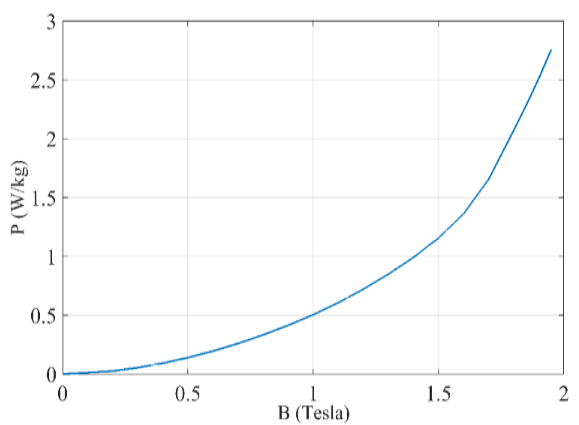

Fig. 8. Power loss curve.

The results clearly show a higher accuracy for the finite element method. The accuracy of the 3-phase threedimensional model is higher than that of the other models. The difference between the 3-phase 3-D and the experimental test is $1.19 \%$. The difference between the single-phase 3-D model and the experimental method is $4.5 \%$. As shown in Table II, the difference between the two- and three-dimensional models is very small or negligible, i.e., the results of the 3-phase 3-D and 3-phase 2$\mathrm{D}$ are very similar, and the results of the 1-phase 3-D and 1phase 2-D are also almost the same. The difference between the prototype transformer and the analytical method is $6.67 \%$. The difference between the 3-phase models and the analytical method is greater than $7.76 \%$, and the difference between the 1-phase models and the analytical method is greater than $10.70 \%$.

Transient analysis is also performed for the evaluation of the magnetic flux density and core losses. Figures 9 and 10 show the magnetic flux density and core losses of the zigzag transformer using 3-phase two-dimensional model.

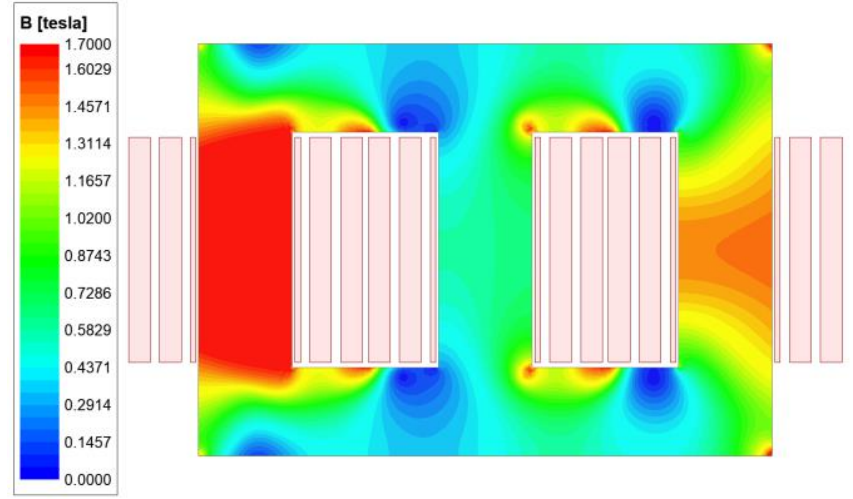

Fig. 9. Magnetic flux distribution of the analysed zigzag transformer.

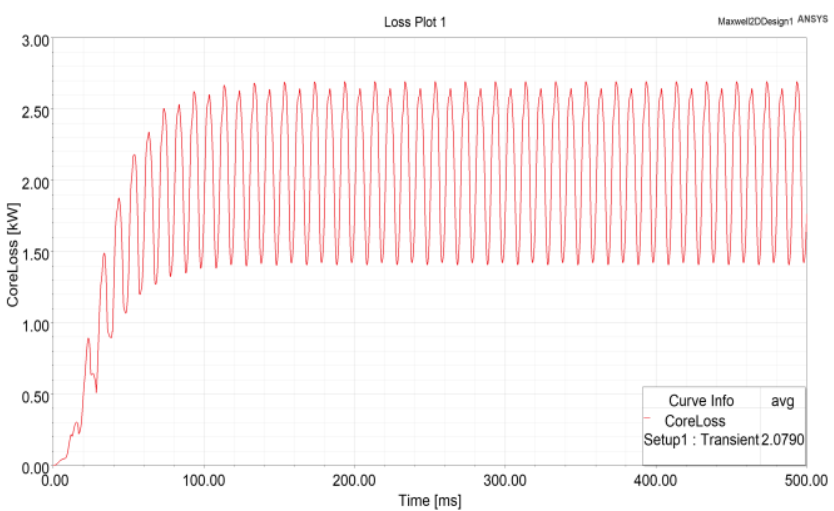

Fig. 10. Core losses of the analysed zigzag transformer.

Table III compares the results of the no-load losses using finite element 2-D three-phase model and experimental test.

TABLE III. CORE LOSS CALCULATION.

\begin{tabular}{|c|c|}
\hline Method & Core loss (kW) \\
\hline FEM 2D & 2079 \\
\hline Experimental & 2020 \\
\hline
\end{tabular}

The difference between the finite element 2-D threephase model and the experimental method is less than $3 \%$.

During the manufacturing of the transformer, an accurate calculation of short-circuit reactance is crucial because it increases the credibility of the manufacturer and the reliability of the transformer. It also helps to reduce the cost and size of the material, since a smaller leakage impedance design margin can be used [22]. Transformer designers mainly rely on analytical formulas. However, the results show that the finite element method is more reliable for calculating the leakage reactance in the zigzag transformer.

The accurate calculation of the leakage reactance and core losses using the finite element method not only helps to evaluate these parameters, but can also be used to optimize the design of the zigzag transformer, which will also help to fulfil the customer requirements and international standards.

\section{CONCLUSIONS}

Appropriate calculation of the leakage reactance is vital for transformer designers because the short-circuit current of the transformer is mainly dependent on the leakage reactance. The overall cost of the transformer can also be minimized by appropriately calculating the leakage reactance.

In this study, the leakage reactance is calculated using experimental tests, numerical techniques, and the analytical method. Several finite element models, namely 3-phase 3D, 1-phase 3D, 3-phase 2D, and 1-phase 2D, are examined for leakage reactance, and these models have been compared with the experimental test and analytical method. Among the analytical techniques, the Rogowski method is used for the evaluation of the leakage reactance. On the other hand, prototype experiment tests are performed to find the exact solution. By using analytical techniques, the leakage reactance can be calculated in a short time and without any financial problems as most of the finite element method software is expensive and time-consuming. However, the accuracy of the finite element models is much higher than that of the analytical method. 
This work will help researchers and transformer designers evaluate and understand different parameters of the leakage reactance by using analytical formulas and finite element models.

\section{ACKNOWLEDGMENT}

The authors thank the Astor Transformer Turkey for making the prototype of the transformer.

\section{CONFLICTS OF INTEREST}

The authors declare that they have no conflicts of interest.

\section{REFERENCES}

[1] P. P. Khera, "Application of zigzag transformers for reducing harmonics in the neutral conductor of low voltage distribution system", Conference Record of the 1990 IEEE Industry Applications Society Annual Meeting, 1990, p. 1092, vol. 2. DOI: 10.1109/IAS.1990.152320.

[2] S. K. Shaikh, A. M. Mulla, S. U. Bagwan, and Y. A. Makandar, "Analysis and application of zigzag transformer in distribution system for mitigation of triplen harmonics", in Proc. of 2020 5th International Conference on Communication and Electronics Systems (ICCES), 2020, pp. 94-98. DOI 10.1109/ICCES48766.2020.9137857.

[3] A. Ahmad, R. Omar, and M. Sulaiman, "Application of zigzag transformers to mitigate triplen harmonics in 3 phase 4 wire Electrical distribution system", in Proc. of 2006 4th Student Conference on Research and Development, 2006, pp. 266-269. DOI 10.1109/SCORED.2006.4339351.

[4] L. Beverly, R. Hance, A. Kristalinski, and A. Visser, "Comments about the use of a zig-zag transformer to reduce the neutral current created by unbalanced non-linear", Fermi National Accelerator Laboratory, Batavia, Illinois, Rep. FNAL-TM-1854, Sep. 1993. DOI 10.2172/10192683

[5] K. Karthi, R. Radhakrishnan, J. M. Baskaran, and L. S. Titus, "Role of zigzag transformer on neutral current reduction in three phase four wire power distribution system", in Proc. of 2017 International Conference on Intelligent Computing, Instrumentation and Contro Technologies (ICICICT), 2017, pp. 138-141. DOI: 10.1109/ICICICT1.2017.8342548.

[6] R. Schlesinger and J. Biela, "Comparison of analytical models of transformer leakage inductance: Accuracy versus computational effort", IEEE Transactions on Power Electronics, vol. 36, no. 1, pp. 146-156, Jan. 2021. DOI: 10.1109/TPEL.2020.3001056.

[7] M. Jaraczewski and T. Sobczyk, "Leakage inductances of transformers at arbitrarily located windings", Energies, vol. 13, no. 23, p. 6464, 2020. DOI: 10.3390/en13236464.

[8] W. Lu, J. Ma, and B. Ma, "Research on winding deformation detection and diagnosis technology of power transformer", Journal of Physics: Conference Series, vol. 1453, art. ID 012114, 2020. DOI: 10.1088/1742-6596/1453/1/012114.
[9] J. Song, "Actual measurement and analysis of power transformer dynamic stability diagnosis by low voltage reactance method based on short circuit test check", in Proc. of 2020 IEEE Conference on Telecommunications, Optics and Computer Science (TOCS), 2020, pp. 104-108. DOI: 10.1109/TOCS50858.2020.9339613.

[10] A. Qayyum, A. s. Larik, and M. A. Mahar, "Performance investigation of six pulse rectifier with transformer vector groups", International Journal of Electrical Engineering \& Emerging Technology, vol. 2, no. 1, pp. 43-47, 2019.

[11] K. Dawood, B. Alboyaci, M. A. Cinar, and O. Sonmez, "A new method for the calculation of leakage reactance in power transformers", J. of Elect. Eng. \& Tech., vol. 12, no. 5, pp. 1883 1890, 2017. DOI: 10.5370/JEET.2017.12.5.1883.

[12] R. L. Castañeda Hernandez, G. A. Diaz Florez, J. J. Perez Gelves, and E. E. Mombello, "Analytic formulation for the calculation of leakage reactance in wound-core transformers", Inter. J. of Appl. Electromagn. and Mechanics, vol. 65, no. 2, pp. 197-213, 2021. DOI: 10.3233/JAE-190140.

[13] W. Rogowski, "Ueber das streufeld und den streuinduktionskoeffizienten eines transformators mit scheibenwicklung und geteilten endspulen", Ph.D. dissertation, Technische Hochschule zu Danzig, Danzig, Berlin, 1908.

[14] X. Margueron, A. Besri, P.-O. Jeannin, J.-P. Keradec, and G. Parent, "Complete analytical calculation of static leakage parameters: A step toward HF transformer optimization", IEEE Trans. Ind. Appl., vol. 46, no. 3, pp. 1055-1063, 2010. DOI: 10.1109/TIA.2010.2045327.

[15] T. Sobczyk and M. Jaraczewski, "On simplified calculations of leakage inductances of power transformers", Energies, vol. 13, no. 18, p. 4952, 2020. DOI: 10.3390/en13184952.

[16] K. Dawood and G. Komurgoz, "Analytical and numerical estimation of the leakage reactance in the sandwich winding transformers", in Proc. of 2020 6th International Conference on Electric Power and Energy Conversion Systems (EPECS), 2020, pp. 75-79. DOI 10.1109/EPECS48981.2020.9304948.

[17] K. Dawood, M. A. Cinar, B. Alboyaci, and O. Sonmez, "Calculation of the leakage reactance in distribution transformers via numerical and analytical methods", Journal of Electrical Systems, vol. 15, no. 2, pp. 213-221, 2019.

[18] S. V. Kulkarni and S. A. Khaparde, Transformer Engineering: Design, Technology, and Diagnostics. CRC Press, 2017. DOI: 10.1201/b13011.

[19] V. Novickij, A. Grainys, G. Staigvila, S. Tolvaisiene, T. Ustinavicius, and J. Novickij, "Design and optimization of pulsed magnetic field generator for cell magneto-permeabilization", Elektronika ir Elektrotechnika, vol. 23, no. 2, pp. 21-25, 2017. DOI 10.5755/j01.eie.23.2.17994.

[20] A. Ozdil and Y. Uzun, "Design and Analysis of a Rotor for a $22 \mathrm{~kW}$ Transversally Laminated Anisotropic Synchronous Reluctance Motor, Elektronika ir Elektrotechnika, vol. 27, no. 1, pp. 17-24, 2021.DOI 10.5755/j02.eie.29046.

[21] K. Dawood, A. K. Köseoğlu, and G. Kömürgöz, "Design optimisation for distance between additional and tap winding in high-voltage transformers", High Voltage, vol. 5, no. 6, pp. 716-723, 2020. DOI: 10.1049/hve.2019.0149

[22] P. S. Georgilakis, Spotlight on Modern Transformer Design. London, UK, Springer, 2009. DOI: 10.1007/978-1-84882-667-0. 